\title{
Metallic stent and flexible bronchoscopy without fluoroscopy for acute respiratory
} failure

\author{
S-M. Lin*,\#, T-Y. Lin**, C-L. Chou*, H-C. Chen*, C-Y. Liu*, C-H. Wang*, H-C. Lin*, \\ C-T. Yu*, K-Y. Lee* and H-P. Kuo*
}

ABSTRACT: Stent implantation has been reported to facilitate liberation from mechanical ventilation in patients with respiratory failure due to central airway disease. The present retrospective cohort study sought to evaluate the risk and benefit of stent implantation via bronchoscopy without fluoroscopic guidance in mechanically ventilated patients.

From July 2001 to September 2006, 26 patients with acute respiratory failure were recruited. A bronchoscope was inserted through a mouth guard into the space between the tracheal wall and the endotracheal tube. A guide wire was inserted via the flexible bronchoscope to the lesion site. The bronchoscope was reintroduced through the endotracheal tube. Under bronchoscopic visualisation, the delivery catheter was advanced over the guide wire to deploy the stent.

These procedures were successfully performed in 26 patients, with 22 stents placed in the trachea and seven in the main bronchus. Of the 26 patients, $14(53.8 \%)$ became ventilator independent during their stay in the intensive care unit. Severe pneumonia was the most common cause, in seven $(58.3 \%)$ out of 12 patients, for continued ventilator dependence after stenting. Granulation tissue formation was found in seven patients during the follow-up period.

It is concluded that metallic stents can be safely implanted without fluoroscopic guidance in patients with respiratory failure, to facilitate ventilator independence.

KEYWORDS: Bronchoscopy, respiratory failure, stent, Ultraflex

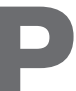

atients who have symptoms associated with central airway lesions should be treated with a multidisciplinary approach, including surgical, medical and endoscopic intervention [1-3]. Self-expandable metallic stents (SEMSs) have been widely used in the past decade to treat patients with benign and malignant airway diseases. They have been successfully implanted using a flexible bronchoscope while the patient received conscious sedation and a local anaesthetic [4-6]. Due to potentially hazardous complications, the US Food and Drug Administration (FDA) has warned that SEMS implantation should be considered only if the patient is not eligible for surgery, rigid bronchoscopy or silicone stent implantation. For patients who are not candidates for surgery or general anaesthesia, SEMS implantation may provide a good alternative [7]. Covered SEMSs have been used to seal off tracheo-oesophageal fistulas and to avoid aspiration symptoms [8-10].

Among patients with obstruction of the trachea and main stem bronchi, respiratory failure is one of the most severe complications. Due to advances in endobronchial stents and insertion techniques, interventional bronchoscopic procedures have been reported to facilitate weaning from mechanical ventilation [11-14]. Rigid bronchoscopy under general anaesthesia and flexible bronchoscopy under fluoroscopic guidance are the most common methods of stent implantation in mechanically ventilated patients. Some patients, however, are not candidates for surgical intervention or rigid bronchoscopy with a general anaesthetic because of illness severity and comorbidities or because they refuse surgery. In addition, fluoroscopy requires special facilities that may not be available in every intensive care unit (ICU). Therefore, the present authors have developed a modified procedure to implant stents using flexible bronchoscopy without fluoroscopic guidance in mechanically ventilated patients in the ICU at the Chang Gung Memorial Hospital (Taipei, Taiwan).

The current study was designed to evaluate the safety, efficacy and complications of this procedure.

\section{AFFILIATIONS}

*Dept of Thoracic Medicine, Chang Gung Memorial Hospital, Chang Gung University, College of Medicine, Taipei, Taiwan.

${ }^{\#}$ Both authors contributed equally to this article.

CORRESPONDENCE

H-P. KuO

Dept of Thoracic Medicine

Chang Gung Memorial Hospital

199 Tun-Hwa N. Rd

Taipei

Taiwan

Fax: 88633272474

E-mail: 98828@ms11.hinet.net

Received:

August 032007

Accepted after revision:

December 132007

STATEMENT OF INTEREST

None declared.

European Respiratory Journa Print ISSN 0903-1936 Online ISSN 1399-3003 
Furthermore, the possible causes of failure of the procedure to eliminate the need for a mechanical ventilator were identified.

\section{MATERIALS AND METHODS \\ Patient recruitment}

From July 2001 to September 2006, 29 tracheobronchial stents were implanted in 26 consecutive patients with respiratory failure associated with central airway obstruction or fistula in an ICU of a tertiary hospital. Informed consent was obtained from each patient or their guardian prior to this procedure. Most of the patients (21 out of 26) had malignant diseases at an advanced stage, with or without complications. For those with benign lesions, other medical conditions or complications precluded some of them from surgical correction. Due to illness severity, high surgical risk or surgical refusal, none of these patients were candidates for surgery or stent implantation under rigid bronchoscopy. Patients' baseline characteristics are shown in table 1 . Ventilator liberation was defined as successful if re-intubation was not required within $48 \mathrm{~h}$ after endotracheal extubation.

\section{Bronchoscopic procedure}

Ultraflex SEMSs (Boston Scientific, Natick, MA, USA) were used in all patients in the present study. All patients underwent SEMS implantation by means of flexible bronchoscopy without fluoroscopic guidance. The length and type of stent to be used (with or without cover) were evaluated by endoscopic examination and chest computed tomography (CT) scan, if a CT scan was available before stent implantation. Each patient underwent fibreoptic bronchoscopy as previously described [15]. Briefly, sedation with intravenous midazolam $(5 \mathrm{mg})$ and a local anaesthetic with $2 \%$ xylocaine solution were administrated prior to bronchoscopy. The bronchoscope was inserted first through a mouth guard into the space between the tracheal wall and the endotracheal tube. The bronchoscope was navigated to the proximal end of the lesion (fig. 1a). If the lesion was at a level higher than the tip of the endotracheal tube, the endotracheal tube was withdrawn to provide an adequate view and space for stent implantation. A guide wire was inserted via the bronchoscope and passed through the lesion (fig. 1b). The bronchoscope was withdrawn, leaving the guide wire at the lesion site (fig. 1c). The bronchoscope was then reintroduced into the endotracheal tube to inspect the location of the guide wire. Under bronchoscopic visualisation, the delivery catheter (Boston Scientific) was advanced over the guide wire to deploy the stent (fig. 1d). The delivery catheter, guide wire and bronchoscope were then withdrawn, leaving the stent in the lesion site (fig. 1e). After completion of stent deployment, the bronchoscope was introduced to check the position of the stent. If distal fine-positioning was required, biopsy forceps (FB-15C-1; Olympus, Tokyo, Japan) were used to hold the distal ring of the stent and push the stent forwards to adjust the position. If proximal fine-positioning was required, the biopsy forceps were introduced to hold the proximal ring of the stent and pull it backwards to adjust the position. The fine-positioning procedures were only feasible before full expansion of the stents $(<24-48 \mathrm{~h}$ after stenting).

The majority of stents could be assessed by direct bronchoscopy visualisation following the deployment of the stent. For larger diameter stents, a bronchoscope and guide wire were used to determine the location and length of the stent. The delivery catheter was marked with the same scale and the stent was deployed when it reached the predetermined level. The position of the stent was assessed by bronchoscopy and chest radiographical study to ensure correct positioning of the stent.

\section{Assessment of stent condition}

Each patient underwent bronchoscopic examination 1 week after SEMS implantation, and then every 3-6 months thereafter, to evaluate the position and integrity of the stent and granuloma formation. The alignment of the airway was assessed before and after stent implantation. If breathlessness, intractable coughing, increased mucus production or stentrelated symptoms occurred, additional bronchoscopic examination was performed for further assessment.

\section{Statistical analysis}

Data were expressed as mean \pm SD. The factors potentially associated with successful liberation from mechanical ventilation were compared using the Fisher exact test. Odds ratios and their $95 \%$ confidence intervals were used to assess the difference.

\section{RESULTS}

The patients' baseline characteristics are summarised in table 1. All procedures were performed successfully. The procedure time was $24.2 \pm 8.8 \mathrm{~min}$. During the procedure, $100 \%$ oxygenation and assistant/control mode-ventilator support were given to the patients. All the patients underwent pulse oxymeter and arterial line monitoring for oxygen saturation and blood pressure, respectively. There was no desaturation $<90 \%$ or hypotension (systolic blood pressure $<90 \mathrm{mmHg}$ ) requiring medical intervention during or after the procedure. Malignant diseases contributed to lesions in 21 patients; oesophageal cancer was the most common aetiology, followed by lung cancer and buccal cancer. The locations and causes of central airway lesions are summarised in table 2.

\section{TABLE 1 Baseline characteristics}

$\begin{array}{lc}\text { Subjects } \mathbf{n} & 26 \\ \text { Sex M/F } \mathbf{n} & 19 / 7 \\ \text { Age yrs } & 63.6 \pm 15.8 \\ \text { APACHE II score } & 17.4 \pm 4.1 \\ \text { Causes of airway lesion } & \\ \quad \text { Malignant lesions } & 21(80.8) \\ \quad \text { Oesophageal cancer } & 11(42.3) \\ \quad \text { Lung cancer } & 5(19.2) \\ \text { Buccal cancer } & 2(7.7) \\ \quad \text { Thyroid cancer } & 1(3.8) \\ \quad \text { Mediastinal schwannoma } & 1(3.8) \\ \quad \text { Mediastinal carcinoid tumour } & 1(3.8) \\ \text { Benign lesions } & 5(19.2) \\ \quad \text { Dynamic collapse of right main bronchus } & 2(7.7) \\ \text { Post-intubation tracheal stenosis } & 1(3.8) \\ \text { Tracheal stenosis (unknown origin) } & 1(3.8) \\ \text { Tracheo-oesophageal fistula (unknown origin) } & 1(3.8)\end{array}$

Data presented as mean \pm SD or $n(\%)$, unless otherwise stated. M: male; $F$ female; APACHE: Acute Physiology and Chronic Health Evaluation. 

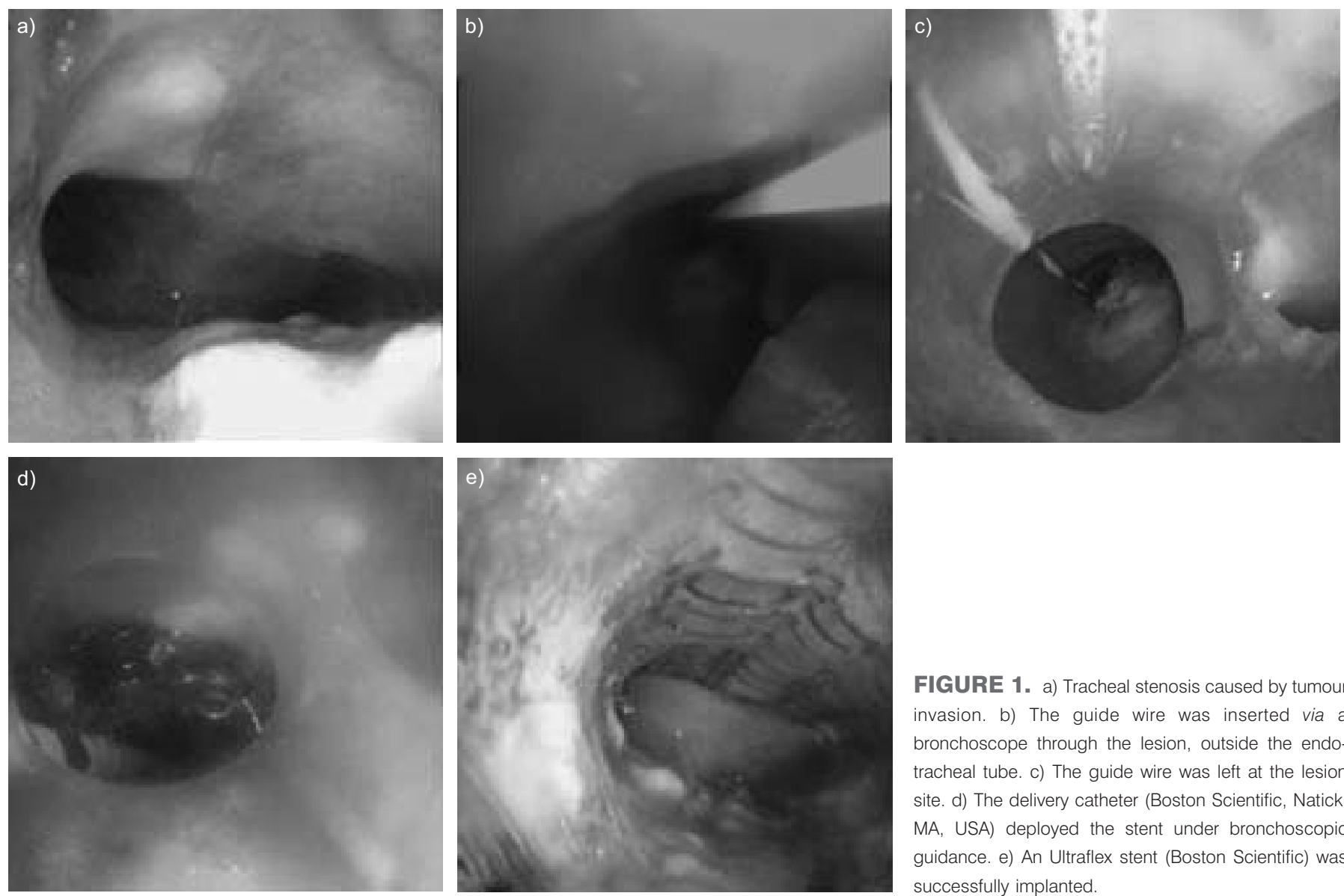

FIGURE 1. a) Tracheal stenosis caused by tumour invasion. b) The guide wire was inserted via a bronchoscope through the lesion, outside the endotracheal tube. c) The guide wire was left at the lesion site. d) The delivery catheter (Boston Scientific, Natick, MA, USA) deployed the stent under bronchoscopic guidance. e) An Ultraflex stent (Boston Scientific) was successfully implanted.

Tracheo-oesophageal fistula, tumour invasion and tumour compression were the three most common causes for stent implantation. The 22 tracheal stents were of varying size $(16 \times 40 \mathrm{~mm} \quad(n=1), 16 \times 80 \mathrm{~mm} \quad(\mathrm{n}=2), 18 \times 40 \mathrm{~mm}(\mathrm{n}=3)$, $18 \times 60 \mathrm{~mm}(\mathrm{n}=8), 20 \times 60 \mathrm{~mm}(\mathrm{n}=4)$ and $20 \times 80 \mathrm{~mm}(\mathrm{n}=4))$ and were chosen according to lesion size; two stents were uncovered. The seven main bronchus stents were of varying size as follows: $10 \times 40 \mathrm{~mm} \quad(\mathrm{n}=1), 12 \times 40 \mathrm{~mm} \quad(\mathrm{n}=1)$, $14 \times 40 \mathrm{~mm}(\mathrm{n}=3), 16 \times 60 \mathrm{~mm}(\mathrm{n}=1)$ and $18 \times 60 \mathrm{~mm}(\mathrm{n}=1)$; all were covered.

The time between development of respiratory failure and stent implantation was 3-25 days (median 5.5 days). After stent implantation, $14(53.8 \%)$ patients were successfully liberated from ventilators. Figure 2 shows the percentage of patients remaining on mechanical ventilation up to 30 days after stent implantation. Among the patients who were successfully liberated from ventilators, $13(92.9 \%)$ were liberated from the ventilator within 1 day of stent implantation, and one patient became ventilator independent 8 days after stent implantation. Of these 14 patients, 13 were transferred to a lower-level care unit (e.g. ordinary ward or respiratory care centre); the time until transfer to this lower-level care ranged from 1-119 days (median 5 days). The overall mortality rate was 57.7\%; for patients successfully and unsuccessfully liberated from ventilation, rates were 35.7 and $83.3 \%$, respectively. The median (range) length of survival of the whole cohort was 30.5 (3473) days; the length of survival of patients who were ventilator independent and ventilator dependent was 34.5 (9473) days and 21.0 (3-159) days, respectively.

The factors potentially associated with liberation from mechanical ventilation are listed in table 3 . However, none of these factors appeared to be different between patients with

\section{TABLE 2 Locations and causes of central airway lesions}

\begin{tabular}{|c|c|c|c|c|c|}
\hline Location & Tumour compression & Tumour invasion & T-E fistula & Dynamic collapse & Tracheal stenosis \\
\hline Trachea & 6 & 5 & 6 & 0 & 2 \\
\hline Right main bronchus & 0 & 1 & 0 & 2 & 0 \\
\hline Left main bronchus & 0 & 2 & 2 & 0 & 0 \\
\hline
\end{tabular}

T-E fistula: tracheo-oesophageal fistula. 


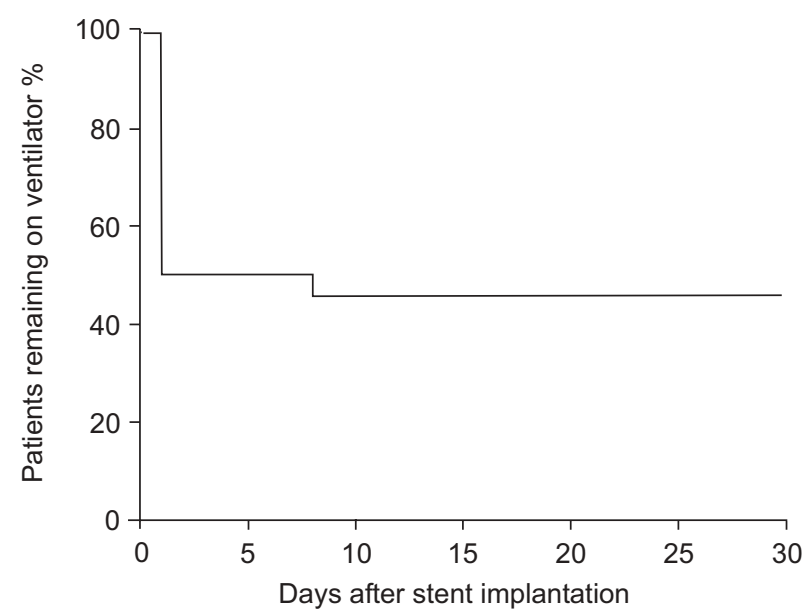

FIGURE 2. The percentage of patients remaining on mechanical ventilation after stent implantation. Of 26 patients, 14 (53.8\%) were ventilator independent after stent implantation; 13 of these were free from the ventilatory support within 1 day of stent implantation.

ventilator liberation success and those with ventilator liberation failure. The causes of ventilator liberation failure are shown in table 4. Complications related to stent implantation are listed in table 5. Granulation tissue formation was found in seven patients, during follow-up periods of up to 473 (median 30.5) days. Symptomatic mucus plugging occurred in one patient and was resolved after a subsequent bronchoscopic procedure. Stent migration developed in one patient, and the stent was adjusted in a second bronchoscopic procedure. An episode of pneumothorax occurred $2 \mathrm{~h}$ after stent implantation in one patient, which resolved spontaneously.

\section{DISCUSSION}

The newly developed method of SEMS implantation, using flexible bronchoscopy without fluoroscopic guidance, was successful in all patients with acute respiratory failure due to central airway lesions. The time required for stent implantation was $24.2 \pm 8.8 \mathrm{~min}$. Successful ventilator liberation after stent

\begin{tabular}{|c|c|c|c|c|}
\hline $\begin{array}{l}\text { Analys } \\
\text { succes }\end{array}$ & $\begin{array}{l}\text { sis of facto } \\
\text { ssful libera }\end{array}$ & $\begin{array}{l}\text { potent } \\
\text { n from }\end{array}$ & $\begin{array}{l}\text { y associated v } \\
\text { echanical vent }\end{array}$ & $\begin{array}{l}\text { vith } \\
\text { ilation }\end{array}$ \\
\hline Factor & Successful & Failed & OR $(95 \% \mathrm{Cl})$ & p-value \\
\hline Subjects n & 14 & 12 & & \\
\hline Severe pneumonia & $5(35.7)$ & $7(58.3)$ & $0.40(0.08-7.04)$ & 0.431 \\
\hline $\begin{array}{l}\text { Tracheo-oesophageal } \\
\text { fistula }\end{array}$ & $2(14.3)$ & $4(33.3)$ & $0.33(0.05-2.27)$ & 0.857 \\
\hline $\begin{array}{l}\text { Endobronchial tumour } \\
\text { invasion }\end{array}$ & $4(28.6)$ & $4(33.3)$ & $0.80(0.15-4.25)$ & 1.00 \\
\hline $\begin{array}{l}\text { External tumour } \\
\text { compression }\end{array}$ & $5(35.7)$ & $2(16.7)$ & $2.76(0.43-18.05)$ & 0.391 \\
\hline $\begin{array}{l}\text { Lesion located in } \\
\text { trachea }\end{array}$ & $12(85.7)$ & $7(58.3)$ & $4.29(0.65-28.28)$ & 0.190 \\
\hline
\end{tabular}

Data presented as $\mathrm{n}(\%)$, unless otherwise stated. OR: odds ratio; $\mathrm{Cl}$ : confidence interval. implantation was achieved in $53.8 \%$ of patients. Severe pneumonia was the most common cause for ventilator liberation failure. No life-threatening complications developed as a result of this procedure.

The average diameter of the adult trachea is $>20 \mathrm{~mm}$ [16]. The inner diameter of an endotracheal tube is $7.5 \mathrm{~mm}$ and the outer diameter is $10-11 \mathrm{~mm}$. Given the elastic character of the trachea, when using a 7.26-mm diameter No. 22Fr delivery catheter (Boston Scientific), there was enough space for the catheter carrying the stent to pass outside the endotracheal tube. The average time for stent implantation was $24.2 \mathrm{~min}$. The risks of thoracic surgery and radiation exposure during fluoroscopy were avoided using the present method. The use of flexible rather than rigid bronchoscopy for airway stent implantation has long been a subject of debate [17, 18]. Both techniques have advantages in different respects. Rigid tools provide a wide view of the operating space. Silicone and dynamic stents are designed to be implanted using a rigid bronchoscope. Flexible bronchoscopy with fluoroscopic guidance allows more pneumologists to perform stent implantation, thus averting operating room costs and the risks of general anaesthesia [4]. Unlike fluoroscopy, the method described in the present study provided direct visualisation of stent deployment, which decreases the chance of stent malpositioning. The use of the present technique also provides broader accessibility for mechanically ventilated patients unsuitable for surgery, and would be a viable alternative when surgical or fluoroscopic equipment is not available.

The easy accessibility of flexible bronchoscopy has made SEMSs increasingly popular [7, 19, 20]. Due to potential complications and the difficulty of removing Ultraflex SEMSs from patients with benign lesions, the US FDA has warned that SEMS implantation should only be considered for patients with benign lesions if they are not candidates for surgery, rigid bronchoscopy or silicone stent implantation. All patients in the present study were in a critical condition; therefore, general anaesthesia, rigid bronchoscopy and subsequent silicone stent implantation were not feasible.

The ventilator liberation rate in the present study was $53.8 \%$, which is similar to that obtained in a previous study [12] Among the causes of ventilator liberation failure after stenting, severe pneumonia was the most common reason. Pneumonia is a frequent complication in patients with central airway

\begin{tabular}{|c|c|c|}
\hline TABLE 4 & \multicolumn{2}{|c|}{$\begin{array}{l}\text { Factors associated with failure to liberate from } \\
\text { ventilation after stent implantation }\end{array}$} \\
\hline \multicolumn{3}{|l|}{ Variables } \\
\hline \multicolumn{2}{|c|}{ Severe pneumonia } & $7(58.3)$ \\
\hline \multicolumn{2}{|c|}{ Vocal cord paralysis due to buccal tumour invasion } & $1(8.3)$ \\
\hline \multicolumn{2}{|c|}{ Laryngeal oedema } & $1(8.3)$ \\
\hline \multicolumn{2}{|c|}{ Chronic asthma with poor pulmonary function } & $1(8.3)$ \\
\hline \multicolumn{2}{|c|}{ Congestive heart failure } & $1(8.3)$ \\
\hline \multicolumn{2}{|c|}{ Gastrointestinal bleeding with hypovolumic shock } & $1(8.3)$ \\
\hline
\end{tabular}

Data presented as $\mathrm{n}(\%)$ of the 12 patients with failed ventilator liberation. 


\begin{tabular}{ll}
\hline TABLE $\mathbf{5}$ & $\begin{array}{l}\text { Complications of stent implantation in all study } \\
\text { patients }\end{array}$ \\
\hline Complication & $7(26.9)$ \\
\hline Granulation tissue formation & $1(3.8)$ \\
Mucus plugging & $1(3.8)$ \\
Pneumothorax & $1(3.8)$ \\
Stent migration & \\
\hline Data presented as $\mathrm{n}(\%)$.
\end{tabular}

disease, due to inadequate drainage of secretions. The implantation of an SEMS should be assessed carefully in these patients, especially if the lobes involved are not directly related to the obstructed airway. Using this new method of stent implantation, a multicentre prospective study is essential for investigation of the factors leading to ventilator liberation failure among patients with respiratory failure due to central airway disease.

In the present study, the incidence of granulation tissue formation $(26.9 \%)$ after stent implantation was similar to that previously reported in mechanically ventilated patients [14]. Pneumothorax occurred in one patient after stent implantation but resolved spontaneously. Interventional bronchoscopy has the inherent risk of causing pneumothorax when positive pressure ventilation is used [21]. In addition, the elevated airway pressure caused by the bronchoscope and delivery catheter in the trachea may also contribute to the development of pneumothorax.

In conclusion, the current study describes a new method of stent implantation in mechanically ventilated patients with central airway lesions. This method is potentially safe and time saving, and facilitates ventilator independence for the patient. Severe pneumonia may be a negative factor for ventilator discontinuation after airway stenting.

\section{REFERENCES}

1 Seijo LM, Sterman DH. Interventional pulmonology. N Engl J Med 2001; 344: 740-749.

2 Bolliger CT, Mathur PN, Beamis JF, et al. ERS/ ATS statement on interventional pulmonology. European Respiratory Society/American Thoracic Society. Eur Respir J 2002; 19: 356-373.

3 Brichet A, Verkindre C, Dupont J, et al. Multidisciplinary approach to management of postintubation tracheal stenoses. Eur Respir J 1999; 13: 888-893.

4 Hautmann H, Bauer M, Pfeifer KJ, Huber RM. Flexible bronchoscopy: a safe method for metal stent implantation in bronchial disease. Ann Thorac Surg 2000; 69: 398-401.

5 Madden BP, Loke TK, Sheth AC. Do expandable metallic airway stents have a role in the management of patients with benign tracheobronchial disease? Ann Thorac Surg 2006; 82: 274-278.

6 Madden BP, Datta S, Charokopos N. Experience with Ultraflex expandable metallic stents in the management of endobronchial pathology. Ann Thorac Surg 2002; 73: 938-944.

7 Saad CP, Murthy S, Krizmanich G, Mehta AC. Selfexpandable metallic airway stents and flexible bronchoscopy: long-term outcomes analysis. Chest 2003; 124: 1993-1999.

8 Freitag L, Tekolf E, Steveling H, Donovan TJ, Stamatis G. Management of malignant esophagotracheal fistulas with airway stenting and double stenting. Chest 1996; 110: 1155-1160.

9 Shin JH, Song HY, Ko GY, Lim JO, Yoon HK, Sung KB. Esophagorespiratory fistula: long-term results of palliative treatment with covered expandable metallic stents in 61 patients. Radiology 2004; 232: 252-259.

10 Li YD, Li MH, Han XW, Wu G, Li WB., Gastrotracheal and gastrobronchial fistulas: management with covered expandable metallic stents. J Vasc Interv Radiol 2006; 17: 1649-1656.

11 Al-Kattan K, Simonds A, Chung KF, Kaplan DK. Kyphoscoliosis and bronchial torsion. Chest 1997; 111: 1134-1137.

12 Colt HG, Harrell JH. Therapeutic rigid bronchoscopy allows level of care changes in patients with acute respiratory failure from central airways obstruction. Chest 1997; 112: 202-206.

13 Shaffer JP, Allen JN. The use of expandable metal stents to facilitate extubation in patients with large airway obstruction. Chest 1998; 114: 1378-1382.

14 Noppen M, Stratakos G, Amjadi K, et al. Stenting allows weaning and extubation in ventilator- or tracheostomy dependency secondary to benign airway disease. Respir Med 2007; 101: 139-145.

15 Yang MC, Liu WT, Wang $\mathrm{CH}$, et al. Diagnostic value of endobronchial ultrasound-guided transbronchial lung biopsy in peripheral lung cancers. J Formos Med Assoc 2004; 103: 124-129.

16 Breatnach E, Abbott GC, Fraser RG. Dimensions of the normal human trachea. AJR Am J Roentgenol 1984; 142: 903-906.

17 Becker $\mathrm{H}$. Flexible versus rigid bronchoscopic placement of tracheobronchial prostheses (stents): pro flexible bronchoscopy. J Bronchol 1995; 2: 252-256.

18 Freitag L. Flexible versus rigid bronchoscopic placement of tracheobronchial prostheses (stents): pro rigid bronchoscopy. J Bronchol 1995; 2: 248-251.

19 Rodriguez NA, Diaz-Jimenez JP, Edell ES. Silicone stents versus metal stents for management of benign tracheobronchial disease. Con: Metal stents. J Bronchol 2000; 7: 184-187.

20 Gaissert HA, Grillo HC, Wright CD, Donahue DM, Wain JC, Mathisen DJ. Complication of benign tracheobronchial strictures by self-expanding metal stents. J Thorac Cardiovasc Surg 2003; 126: 744-747.

21 Chen KY, Jerng JS, Liao WY, et al. Pneumothorax in the ICU: patient outcomes and prognostic factors. Chest 2002; 122: $678-683$. 